\title{
Constipation-related symptoms and bowel program concerning individuals with spinal cord injury
}

\author{
D Harari ${ }^{1,2}$, M Sarkarati ${ }^{3}, \mathrm{JH}_{\text {Gurwitz }}{ }^{1,2,4}, \mathrm{G}$ McGlinchey-Berroth ${ }^{2}$ and KL Minaker ${ }^{1,2}$ \\ ${ }^{1}$ Division on Aging, Harvard Medical School, and the Massachusetts General Hospital/Beacon Hill Geriatric \\ Medicine Unit and General Medicine Unit; ${ }^{2}$ Geriatric Research Education and Clinical Center, VA Medical Center, \\ Brockton/West Roxbury, MA; ${ }^{3}$ Spinal Cord Injury Service, VA Medical Center, Brockton/West Roxbury, MA; and \\ ${ }^{4}$ Program for the Analysis of Clinical Strategies, Gerontology Division, Brigham and Women's Hospital and Harvard \\ Medical School, MA, USA
}

Purpose. To determine the prevalence of constipation-related symptoms in individuals with chronic spinal cord injury (SCI), to describe the bowel program as reported by patients and including use of bowel medications and evacuation techniques, and to examine the clinical, functional and pharmacological risks of difficulty with evacuation. Patients and Methods. This is a cross-sectional study of all in-patients at least 3 months beyond acute injury, on the West Roxbury/Brockton VAMC SCI Service, during a 10 month period $(n=197)$. Clinical, functional, and medication data were abstracted from medical and nursing records. Individual interviews were conducted with all available participants $(n=161,82 \%)$ regarding bowelrelated symptoms and treatment over the previous 1 month period. The study definition of difficulty with evacuation was spending more than $1 \mathrm{~h}$ per episode of bowel evacuation. Results. Forty-one percent of the 161 interview responders spent more than $1 \mathrm{~h}$ on bowel evacuation, $50 \%$ reported abdominal distension and $38 \%$ reported abdominal pain, $27 \%$ reported headaches or sweats relieved by having a bowel movement, and 33\% reported fecal incontinence at least once a month. The bisacodyl suppository was the most commonly used laxative agent, while docusate was the most popular oral agent. Subjects with difficulty with evacuation $(n=66)$ were compared with those who spent less than $1 \mathrm{~h}$ on evacuation $(n=95)$. Factors associated with difficulty with evacuation were tetraplegia, Frankel grade A/B, laxative use, polypharmacy, previous urinary outlet surgery, and symptoms of abdominal pain and distension. Conclusion. Constipation-related symptoms are highly prevalent in individuals with spinal cord injury, despite considerable laxative use. Our findings suggest that difficulty with evacuation can be predicted on the basis of a patient's clinical profile.

Keywords: spinal cord injury; constipation; bowel program; cathartics; tetraplegia

\section{Introduction}

Constipation is a common problem and an important cause of morbidity in individuals with a spinal cord injury (SCI), ${ }^{1-7}$ yet is has been greatly understudied as a health care issue in this population. Constipation inevitably follows complete cord transection ${ }^{2,8,9}$ or conus medullaris injury, ${ }^{10}$ and frequently proves resistant to conventional treatment in these individuals. $^{10-12}$ Characterization of symptoms associated with constipation in individuals with SCI is limited in the current medical literature, ${ }^{5}$ but it appears that the prevalence of constipation-related symptoms, and the negative impact on lifestyle which they cause, increases in relation to the duration of their disability. 5,13 Individuals may spend from 1 to more than $5 \mathrm{~h}$ a

Correspondence: D Harari, Massachusetts General Hospital Geriatric Medicine Unit, 169 Cambridge St., 100 Charles River Plaza, 5th Floor, Boston, MA 02114, USA day on a routine bowel program, ${ }^{5,11,14}$ which may lead to frustration arising from the limitations that this can place on pursuing social and work-related activities. ${ }^{11,15,16}$ Increasing difficulty with evacuation may also increase the need for professional assistance with the bowel program, which has important resource utilization implications. ${ }^{16}$ Fecal impaction occurs commonly in persons with SCI, ${ }^{2,7}$ and may lead to further complications such as volvulus, ${ }^{6,17,18}$ stercoral perforation, ${ }^{19}$ colonic pseudo-obstruction, ${ }^{6}$ functional ileus, ${ }^{3}$ autonomic dysreflexia, ${ }^{3-5,19}$ dyspnoea, ${ }^{5}$ and worsening spasticity. ${ }^{20}$

The level of the SCI to some extent may determine the pattern and severity of constipation. ${ }^{7,19,21}$ Lumbosacral injury renders the descending colon and rectosigmoid immobile and flaccid, predisposing the patient to distal fecal impaction, with the risk of fecal soiling and incontinence. ${ }^{1,10,22-24}$ Cervicothoracic trauma results in hypertonicity and reduced compli- 
ance of the entire colon, thereby greatly prolonging transit time from cecum to descending colon. $3,8,9,23,25$ However, individual patients with comparable neurological levels of injury may show markedly different patterns of constipation. ${ }^{2,22}$ In particular, as individuals age with cervicothoracic cord injury, the colon may become progressively more compliant and flaccid, predisposing them to worsening constipation symptoms. ${ }^{5}$ There are limited data examining difficulty with evacuation in relation to neurological level of SCI, time elapsed since injury, ${ }^{3}$ and other factors such as age, functional impairment, medications, and comorbidity.

There are surprisingly little descriptive data published on patterns of use of laxatives, suppositories, enemas, and bowel program techniques in patients with chronic SCI. Patients appear to largely selfadminister bowel medications on a trial and error basis. $^{26}$ Although some review articles and book chapters offer general guidelines on bowel care programs, ${ }^{19,21,27,28}$ prescribing physicians may be limited by the paucity of pharmacotherapeutic data regarding constipation in SCI.

The objectives of the present study were to determine the prevalence of constipation-related symptoms in individuals with chronic SCI, to describe use of bowel medications and bowel program characteristics, and to examine clinical, functional and pharmacological correlates of difficulty with evacuation.

\section{Methods}

Data were collected on all individuals with SCI beyond 3 months of acute injury, who received in-patient care on the West Roxbury and Brockton SCI service during the study period of April 1993 - January $1994(n=197)$. The protocol was approved by the Brockton/West Roxbury Research Committee and the Institutional Human Studies Review Committee and written informed consent was obtained from all participants. The following data were abstracted from medical records: age, sex, reason for admisson, date of SCI, pattern of injury (ie tetraplegia or paraplegia), highest level of neurological injury, functional impairment (see below), previous urinary outlet surgery, and diagnosis of diabetes mellitus. Previous urinary outlet surgery has been associated with difficulty with evacuation ${ }^{5}$ and diabetes mellitus can result in prolongation of gut transit time, ${ }^{29}$ particularly in individuals with autonomic neuropathy. ${ }^{30}$ All medications prescribed during the 1 month period prior to the date of data abstraction were also abstracted from the medication record.

All subjects were classified into three discrete hospitalization categories: scheduled annual check-up, acute or sub-acute medical or surgical care, and longterm care. All community-dwelling patients under the care of the West Roxbury/Brockton VAMC SCI Service are scheduled for an annual in-patient checkup, which usually requires a hospital admission of not more than $48 \mathrm{~h}$. Should any patient require medical or surgical services, they may be admitted to the SCI Service at any time. During the study period April 1993 - January 1994, the SCI Service had the following admission profile: $62 \%$ for scheduled annual check-up; $21 \%$ for medical or surgical services; and $17 \%$ in longterm care residency status.

Functional impairment was rated in all subjects using the 5-point Frankel classification which characterizes neurological function below the level of spinal cord injury. ${ }^{31}$ Frankel grade A indicates no motor or sensory function below the level of injury; Frankel B indicates some remaining sensation, but no motor function; Frankel $\mathrm{C}$ indicates some motor function, but not enough to enable the patient to usefully apply motor skills; Frankel D indicates some degree of useful motor function; and Frankel E indicates full motor and sensory function.

A brief interview of each subject was attempted within $48 \mathrm{~h}$ of the date of record abstraction, following written informed consent. Thirty-one individuals were discharged from the facility before the researchers were able to interview them. Two subjects were determined to be incapable of participating in the interview due to impaired cognition, and three subjects refused. Thus, of the 197 potential study participants, interviews were performed on $161(82 \%)$. 'Bowel program' refers to scheduled bowel evacuation with or without use of digital stimulation, laxatives, stool softeners, suppositories or enemas. Subjects were asked to respond to the following questions:

(1) In 1 week, how many times do you do a bowel program?

(2) How much time do you spend moving your bowels (from the time you sit on the toilet to the time you transfer off the toilet)?

(3) Who usually does your bowel program?

(4) Is digital stimulation used to empty your rectum?

(5) How many minutes after inserting a suppository do you have a bowel movement?

(6) In 1 month, how often is your rectum evacuated manually in addition to your bowel program?

(7) In 1 month, how often are you incontinent of feces?

(8) In 1 month, how often do you suffer from abdominal pain relieved by having a bowel movement?

(9) In 1 month, how often do you suffer from abdominal distention relieved by having a bowel movement?

(10) Do you ever have headaches or sweats relieved by having a bowel movement?

(11) Do you find it easier to have a bowel movement in the 15-30 min following a meal or a drink?

(12) Did you use laxatives or enemas before your spinal cord injury?

(13) Can you list all the laxatives, suppositories and enemas you are using at home, and how often you take them? 
Study definitions and analysis

For the purposes of this study, spending more than $1 \mathrm{~h}$ on bowel emptying (in response to the question 'How much time to you spend moving your bowels?'), was referred to as 'difficulty with evacuation'. 'Regular laxative use' was defined as use of at least four doses of laxative per month. The following variables were chosen to investigate possible associative relationships with difficutly with evacuation: age, sex, long-term care, ${ }^{32} 10$ or more years elapsed since injury, ${ }^{5}$ pattern of injury, 7,19,21 highest neurological level of injury, Frankel grade, previous urinary outlet surgery, diagnosis of diabetes mellitus, ${ }^{30}$ self-administered bowel program (versus family member or nurse/ attendant), evacuation induced by meal or drink, headaches or sweats relieved by evacuation, abdominal distention, abdominal pain and fecal incontinence occurring at least once per month, current regular laxative use ( $\geqslant$ four doses per month), ${ }^{33}$ laxative use prior to SCI, current use of at least six medications, ${ }^{34}$ and use of the following specific drug categories: calcium channel blockers, ${ }^{35}$ iron supplements, ${ }^{36}$ antidepressants, ${ }^{37}$ neuroleptics, ${ }^{38}$ baclofen (known to affect gastric motility), ${ }^{20}$ narcotics, ${ }^{39}$ antidiarrheals (loperamide, kaopectate, and lomotil), aluminium- and calcium-containing antacids, ${ }^{33}$ diuretics, angiotensin converting enzyme inhibitors, ${ }^{40}$ and nonsteroidal anti- inflammatory drugs. ${ }^{41}$ Drugs with known anticholinergic properties were examined as a discrete pharmacological variable; this variable included drugs from within the categories of antidepressants (eg amitryptiline, imipramine, doxepin), neuroleptics (eg chlorpromazine, thioridazine, prochloperazine), as well as diphenhydramine, ${ }^{37}$ and urological drugs oxybutynin and propantheline. Chi-square tests were used to examine differences in demographic, clinical and pharmacological characteristics between interview responders and non-participants. $P$ values $<0.05$ were considered significant. Factors shown to have a significant univariate association with difficulty with evacuation were included in a multiple logistic regression analysis. All tests of significance were twotailed.

\section{Results}

Characteristics of interview responders

Table 1 summarizes and compares the characteristics of interview responders $(n=161)$, and non-participants $(n=36)$. The mean age of interview responders was $57 \pm 15$ years, and $97 \%$ of participants were male. The predominance of men reflects the demographic representation of the Veterans Administration popula-

Table 1 Characteristics of interview responders and non-participants

\begin{tabular}{|c|c|c|c|}
\hline Characteristics & $\begin{array}{l}\text { Interview responders } \\
\quad(\mathrm{n}=161)\end{array}$ & $\begin{array}{l}\text { Non-participants } \\
(\mathrm{n}=36)\end{array}$ & $\mathrm{P}$ value \\
\hline Age (years) mean $\pm \mathrm{SD}$ & $57.1 \pm 14.9$ & $54.4 \pm 13.0$ & 0.28 \\
\hline $\operatorname{Sex}(\%$ male $)$ & 96.9 & 100 & 0.28 \\
\hline \multicolumn{4}{|l|}{ Reason for Admission (\%) } \\
\hline Annual check-up & 61.5 & 86.1 & $<0.001$ \\
\hline Acute medical or surgical illness & 21.1 & 8.3 & \\
\hline Long-term care & 17.4 & 5.6 & \\
\hline Years Injured mean \pm SD & $20.4 \pm 13.7$ & $20.9 \pm 13.2$ & 0.83 \\
\hline \multicolumn{4}{|l|}{ Pattern of Injury $(\%)$} \\
\hline Tetraplegia & 53.7 & 50.0 & 0.52 \\
\hline Paraplegia & 46.3 & 50.0 & \\
\hline \multicolumn{4}{|l|}{ Highest Level of Injury (\%) } \\
\hline Cervical & 55.9 & 50.0 & 0.60 \\
\hline Thoracic & 35.4 & 36.1 & \\
\hline Lumbar & 8.7 & 13.9 & \\
\hline \multicolumn{4}{|l|}{ Frankel Grade } \\
\hline A & 48.4 & 47.2 & 0.04 \\
\hline $\mathrm{B}$ & 18.6 & 13.9 & \\
\hline $\mathrm{C}$ & 24.2 & 13.9 & \\
\hline $\mathrm{D}$ & 8.7 & 25.0 & \\
\hline Diabetes mellitus (\%) & 14.3 & 8.3 & 0.34 \\
\hline Urinary outlet surgery (\%) & 43.5 & 38.9 & 0.62 \\
\hline Medications prescribed (mean $\pm \mathrm{SD})$ & $5.9 \pm 4.0$ & $4.8 \pm 3.5$ & 0.80 \\
\hline \multicolumn{4}{|l|}{ Laxative doses taken per month $(\%)$} \\
\hline$<4$ & 30.8 & & \\
\hline $4-30$ & 42.3 & & \\
\hline$>30$ & 26.9 & & \\
\hline Laxative doses taken per month $($ mean $\pm \mathrm{SD})$ & $27.4 \pm 37.9$ & & \\
\hline Laxatives or enemas taken prior to SCI $(\%)$ & 13.0 & & \\
\hline
\end{tabular}


tion, and also the higher incidence of SCI in men. ${ }^{42}$ The average number of years since injury among interview responders was $20.4 \pm 14$. Fifty-four percent of responders were tetraplegic, and the highest neurological level of injury was cervical in $56 \%$, thoracic in $35 \%$ and lumbosacral in $9 \%$. Forty-eight percent of responders were classified as Frankel grade A, 19\% as Frankel B, 24\% as Frankel C and $9 \%$ as Frankel D; there were no individuals classified as Frankel E. Fourteen percent of responders had diabetes mellitus, and $44 \%$ had had previous urinary outlet surgery. An average of $5.9 \pm 4.0$ medications were taken per subject.

The only significant difference between the interview responder and non-participant group was in the reason for admission to the hospital. Sixty-one percent of responders as compared with $86 \%$ of non-participants were admitted for annual check-up, reflecting the primary reason for non-participation which was rapid discharge from hospital, preempting the study interview.

\section{Laxative use among interview responders}

Sixty-nine percent of subjects reported use of at least four laxative, suppository or enema doses per month, at an average number of $27 \pm 38$ doses per month (Table 1). Thirteen percent of interview responsers had used laxatives or enemas prior to the SCI.

Figure 1 displays proportions of the interview responders taking different categories of laxatives. The most popular oral agent, docusate sodium (a fecal softener), was used by $21 \%$ of subjects. Stimulant laxatives (bisacodyl, senna and cascara) were the second most commonly used agents $(16 \%)$, followed by saline laxatives (magnesium hydroxide and magnesium citrate) (14\%), bulk laxatives (methylcellulose and psyllium) (9\%) and lastly hyperosmolar laxatives (lactulose and sorbitol) $(1 \%)$. Forty-one percent of residents reported use of bisacodyl suppositories, and 6\% used enemas.

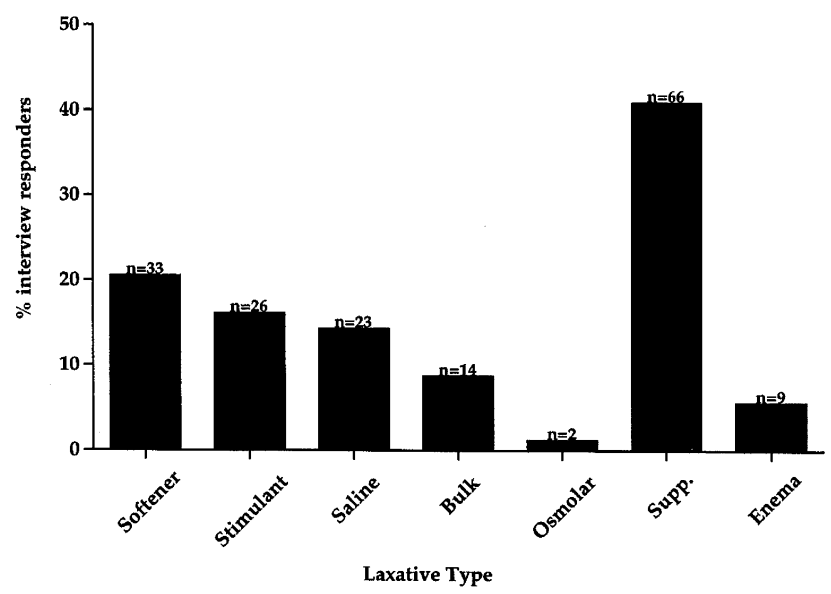

Figure 1 Laxatives, suppositories and enemas, by category, as taken by interview responders $(n=161)$
Bowel-related symptoms of interview responders Among interview responders $41 \%$ reported spending more than $1 \mathrm{~h}$ per bowel evacuation episode, and $12.5 \%$ spent more than $2 \mathrm{~h}$ (Table 2). Of symptoms relieved by evacuation and occurring at least once a month, half of the responders reported abdominal distention, with abdominal pain being the next most common symptom $(38 \%)$. Twenty-seven percent of individuals reported symptoms of autonomic dysreflexia (headaches or sweats) which were relieved by evacuation. One third of individuals described at least one episode of fecal incontinence a month, and $22 \%$ felt that evacuation was facilitated following a meal or a drink.

\section{Characteristics of bowel program}

Most individuals performed a bowel program 3-6 times a week (59\%), though $27 \%$ did so at least once a day (Table 3). Forty-seven of subjects self-administered their bowel program, while the remainder had assistance, mainly from a professional nurse or attendant $(40 \%)$. Only thirty-three percent of responders reported use of digital stimulation. Tweny-one percent of individuals had needed manual evacuation at least once during a 1 month period, in addition to routine bowel program.

Factors associated with difficulty with evacuation

Table 4 lists the clinical, functional, pharmacological and symptom characteristics which were significantly associated with difficulty with evacuation in univariate analysis. Subjects classified as Frankel grade A/B were more likely than those classified as grade $\mathrm{C} / \mathrm{D}$ to

Table 2 Bowel-related symptoms of interview responders

\begin{tabular}{lc}
\hline Bowel-related symptoms & $\begin{array}{c}\text { Interview responders } \\
(\mathrm{n}=161) \%\end{array}$ \\
\hline Time spent on bowel evacuation & \\
$\quad<1$ hour & 59.0 \\
$1-2$ hours & 28.5 \\
$\quad 2$ hours & 12.5 \\
Abdominal pain relieved by & \\
$\quad$ evacuation/month & 62.1 \\
Never & 8.7 \\
Once & 29.2 \\
$>1$ & \\
Abdominal distention relieved by & \\
$\quad$ evacuation/month & 50.3 \\
Never & 8.6 \\
Once & 41.1 \\
$>1$ & 27.3 \\
Headache relieved by evacuation & \\
Fecal Incontinence/month & 67.1 \\
Never & 19.2 \\
Once & 13.7 \\
$\quad>1$ & 21.7 \\
Evacuation induced by meal &
\end{tabular}


have difficulty with evacuation. Subjects with tetraplegia versus paraplegia, and those who had undergone previous urinary outlet surgery were more at risk of difficulty with evacuation. Long-stay residency however placed individuals at a lesser risk of reporting difficulty with evacuation. Regular laxative use ( $\geqslant$ four doses taken per month) was most strongly associated with difficulty with evacuation. Use of at least six medications, and use of benzodiazepines, was also associated. The bowel-related symptom which correlated most strongly with difficulty with evacuation was abdominal distention, followed by abdominal pain.

After inclusion in a multiple logistic regression model, the following factors remained independently associated with difficulty with evacuation: tetraplegia (Adjusted Odds Ratio (AOR) 2.79 95\% Confidence Intervals 1.3-6.2), Frankel grade A or B (AOR 2.77

Table 3 Bowel program characteristics of interview responders

\begin{tabular}{lc}
\hline Bowel program characteristics & $\begin{array}{c}\text { Interview responders } \\
(\mathrm{n}=161) \\
\%\end{array}$ \\
\hline Bowel program/week & 14.0 \\
$0-2$ & 59.0 \\
$3-6$ & 27.0 \\
$\geqslant 7$ & \\
Manual disimpaction required, in & \\
$\quad$ addition to bowel program/month & 77.0 \\
Never & 11.2 \\
Once & 9.8 \\
$>1$ & \\
Who does bowel program & 47.2 \\
Self & 13.0 \\
Family member & 49.8 \\
$\quad$ Nurse/Attendant & 32.9 \\
Digital stimulation & \\
\hline
\end{tabular}

$95 \%$ CI 1.1-6.7), $\geqslant$ four laxative doses taken per month (AOR 2.41 95\% CI 1.0-6.6), and long-term care residency (AOR 0.21 95\% CI 0.1-0.6).

\section{Discussion}

Our findings suggest that persons with chronic spinal cord injury spend a considerable amount of their waking time managing a bowel program, and in addition have a high prevalence of constipationrelated symptoms, particularly abdominal distention, abdominal pain and autonomic dysreflexia relieved by bowel evacuation. People who have difficulty with evacuation use more laxatives, which implies that constipation-related problems persist in these individuals despite considerable levels of pharmacotherapy. The study findings also suggest that numerous clinical factors are associated with difficulty with evacuation among persons with SCI.

Forty-one percent of individuals in this study with chronic SCI spend more than $1 \mathrm{~h}$ per episode of bowel evacuation. Stone et al examined gastrointestinal symptoms in 127 spinal cord injured veterans who were generally younger than this study population (mean age 47, mean time elapsed since injury 12 years), and found that $20 \%$ reported spending more than $1 \mathrm{~h}$ on bowel program. ${ }^{5}$ In a survey of 277 veterans with SCI, Nelson et al found that the average time spent per procedure was 2 h. ${ }^{14}$ Prolonged bowel program has been associated with report of difficulty with evacuation; ${ }^{3,5}$ we found that of those study subjects who used suppositories, $49 \%$ had to wait more than $30 \mathrm{~min}$ following insertion before starting a bowel movement. Physiological studies in spinal cord injured persons reporting difficulty with evacuation have demonstrated significant prolongation of transit through the left colon and rectum..$^{2,3,9,10,43}$ Impairment of rectal sensation, and weakness of the pelvic and abdominal muscles are also likely to predispose patients to reporting this symptom. ${ }^{2,44}$ The finding in

Table 4 Subject characteristics significantly associated with difficulty with evacuation

\begin{tabular}{|c|c|c|c|}
\hline Characteristic & $\begin{array}{c}\text { Subjects who have difficulty } \\
\text { with evacuation } \\
\mathrm{n}=66 \\
\%(\mathrm{n})\end{array}$ & $\begin{array}{c}\text { Subjects who spend }<1 \mathrm{~h} \\
\text { per evacuation } \\
\mathrm{n}=95 \\
\%(\mathrm{n})\end{array}$ & $\begin{array}{l}\text { Relative risk } \\
(95 \% \text { CI })\end{array}$ \\
\hline \multicolumn{4}{|l|}{ Clinical/functional } \\
\hline Frankel A/B & $79(52)$ & $60(56)$ & $1.82(1.1-3.0)$ \\
\hline Urinary outlet surgery & $58(38)$ & $34(32)$ & $1.76(1.2-2.6)$ \\
\hline Tetraplegia & $68(45)$ & $47(45)$ & $1.69(1.1-2.6)$ \\
\hline Long-term care & $12(8)$ & $21(20)$ & $0.66(0.4-1.0)$ \\
\hline \multicolumn{4}{|l|}{ Drugs } \\
\hline$\geqslant 4$ lax doses taken/month & $83(55)$ & $56(53)$ & $2.45(1.4-4.4)$ \\
\hline Benzodiazepines & $59(39)$ & $36(34)$ & $1.72(1.2-2.5)$ \\
\hline$\geqslant 6$ medications prescribed & $59(39)$ & $44(42)$ & $1.43(1.0-2.1)$ \\
\hline \multicolumn{4}{|l|}{ Symptoms } \\
\hline Abdominal distention at least $1 \times /$ month & $59(39)$ & $41(39)$ & $1.56(1.1-2.3)$ \\
\hline Abdominal pain at least $1 \times /$ month & $47(31)$ & $31(29)$ & $1.48(1.0-2.1)$ \\
\hline
\end{tabular}


this and other studies, that individuals with tetraplegia were more likely than those with paraplegia to report difficulty with evacuation, ${ }^{3,5}$ may in part relate to anorectal dyssynergia, a condition seen in some individuals with high lesions, where the internal anal sphincter does not relax despite contraction of the rectum. ${ }^{3}$

The bowel-related symptoms most strongly associated with difficulty with evacuation were abdominal distention and abdominal pain. Stone et al found that postprandial abdominal distention and pain also correlated with difficulty with evacuation, particularly in individuals with lesions above T5. ${ }^{5}$ Symptoms of abdominal distention or pain are especially likely to prompt an individual with SCI to increase the frequency of their bowel program, ${ }^{5}$ or even to accept colostomy as an alternative remedy for symptom relief. ${ }^{12}$ These specific symptoms should be included in a bowel history when assessing constipation in patients with SCI, particularly as it would appear that they may partly drive treatment for this condition. Further research however, is required to examine the relationship between symptoms of abdominal pain and distention and more objective measures of fecal retention. Although symptoms of autonomic dysreflexia did not correlate directly with difficulty with evacuation, we nevertheless found that $27 \%$ of subjects reported headaches or sweats that were relieved by evacuating their bowels. Stone et al observed that $43 \%$ of study subjects reported occasional dysreflexia in association with bowel movements. ${ }^{5}$ People with SCI may sometimes use symptoms of autonomic dysreflexia as a 'trigger' to administer their bowel program. ${ }^{45}$ These symptoms may however indicate the presence of fecal impaction, ${ }^{19}$ and the goal of the overall bowel program should be to eliminate them. In some individuals with SCI, autonomic dysreflexia is a potentially lifethreatening condition which may be remediable through effective bowel care. ${ }^{45,46}$ Twenty-two percent of individuals with chronic SCI reported that bowel evacuation was sometimes induced by ingestion of food or fluids. Physiological studies have generally shown that the postprandial increase in colonic spike potentials corresponding to the gastrocolic reflex, is absent in individuals with cervicothoracic lesions. ${ }^{8,9,47}$ However, these clinical findings would suggest that patients should nevertheless be encouraged to administer their bowel program within 45 min of ingesting a meal, or hot or carbonated fluids.

Our findings showed an association between difficulty with evacuation and use of at least four laxative doses per month. While not conclusive, these data suggest that current pharmacological management of this problem is frequently clinically ineffective, or becomes ineffective over time. The oral agent most commonly used by our study population was the stool softener docusate. Although, to the best of our knowledge there are no published clinical trials of stool softeners in patients with SCI, studies in non-injured subjects demonstrates docusate as having no impact on gut motility or stool volume, and therefore as being ineffective as a laxative. ${ }^{19,32,48-50}$ Likewise, although there are no published data examining the efficacy of stimulant laxatives in persons with SCI, they are likely to be less effective in individuals in whom the colon is hypotonic and excessively compliant, such as those with lumbosacral injuries, ${ }^{21}$ and those with long-standing cervicothoracic injury and acquired megacolon., 99 Saline laxatives, the third most commonly used category of laxative agents, are not generally recommended for use in individuals with SCI, ${ }^{21,27}$ and their rapid onset of action and tendency to induce watery stool, may also promote incontinence. ${ }^{10}$ Surprisingly, bulk laxatives were taken by only $9 \%$ of study participants, even though they are the most frequently recommended laxative agents for use in persons with SCI, ${ }^{19,21,27,28}$ Bulk laxatives both enhance colonic transit and increase fecal water content, ${ }^{19,28,51,52}$ increasing stool volume, and hence facilitating evacuation ${ }^{28,45,51,52}$ Osmolar laxatives may also potentially be underused in persons with SCI, as their efficacy has been clearly demonstrated in noninjured elderly subjects, ${ }^{53-55}$ in whom constipation also tends to be associated with motility abnormalities of the colon and rectum. ${ }^{33,50}$ The frequent use of bisacodyl suppositories by these study participants is appropriate in view of published findings that when properly inserted, ${ }^{56}$ suppositories facilitate evacuation at all levels of SCI. ${ }^{16,19,27,28,44,50,57}$ Enemas were rarely used by interview responders, maybe in part reflecting the need for expert administration required to ensure adequate retention of fluid, 24,27,45,58 and avoidance of damage to the anesthetic rectum, and the external anal sphincter. ${ }^{19,56}$ These study findings describe current patterns of laxative, suppository and enema utilization among persons with SCI, but further research is needed to evaluate the effectiveness and safety of these pharmacotherapeutic regimens for the treatment of constipation in this population.

The finding that residents of the long-term care facility were less likely to report difficulty with evacuation may suggest that highly effective bowel program techniques may reduce constipation-related symptoms, even in those spinal cord injured persons who are older and who carry a greater burden of chronic illness. Incorrect technique, particularly suppository mispositioning and failure to perform preceding manual evacuation where needed, may result in failure to trigger defecation. ${ }^{56}$ While use of digital stimulation is recommended in all patients with cervicothoracic injuries, and in those with lower lesions in whom the anal reflexes are intact, $19,21,27,28,56$ only $33 \%$ of interview responders reported use of this technique. Patients who comply well with a bowel training program tend to have fewer constipation-related symptoms. ${ }^{24,56}$ Our findings that $47 \%$ of individuals, and $13 \%$ of family members 
perform the bowel program emphasizes the importance of regularly reinforced patient and caregiver education on all aspects of bowel management. ${ }^{59}$

Our study suggests that factors other than the SCI may increase the risk of difficult evacuation. Functional classification Frankel grade $\mathrm{A}$ and $\mathrm{B}$ may be associated in part due to the probability of the gut being more severely affected in individuals with complete cord transection, ${ }^{10,23}$ and the greater degree of immobility. ${ }^{5,22}$ Range of motion exercises prior to the bowel program may help to facilitate evacuation in these individuals. ${ }^{22,60}$ Polypharmacy may increase the risk of constipation, especially in older individuals, ${ }^{34}$ and constipation as a drug side-effect may be substantially under-reported in patients with SCI. Benzodiazepines have not previously been shown to increase the risk of constipation in non-injured subjects $^{33,37}$ and this study finding may be confounded by increased administration to individuals who are Frankel grade A or B. The finding that individuals with history of previous urinary outlet surgery had a greater risk of reporting difficulty with evacuation may reflect the shared innervation between bladder and lower gut; hyperreflexic volume-pressure abnormalities have been documented in both the colon and bladder in individuals with cervicothoracic lesions, ${ }^{8,9,23}$ and persons with anorectal dyssynergia also tend to have concomitant bladder detrusorsphincter dyssynergia. ${ }^{3}$ Stone et al found that $72 \%$ of individuals with difficulty with evacuation had had transurethral sphincterotomy. 5 The results of these studies suggest that a history of previous urinary outlet surgery in a patient with SCI should alert the physician to an increased risk of constipation-related problems.

One potential limitation of this study is that report of constipation-related symptoms, however specific, may be slightly subjective. Test-retest evaluations of bowel-symptom questionnaires in non-injured elderly subjects have shown good reliability, ${ }^{34,61}$ though similar validation has not been performed in the spinal-cord injured population. Certain psychosocial and clinical factors which were not measured in this study, such as diet, hydration, physical activity, and patient motivation should be regarded as relevant to constipation in this population.

In conclusion, constipation-related symptoms are highly prevalent in individuals with chronic spinal cord injury, despite considerable laxative use. Our findings suggest that difficulty with evacuation can be predicted on the basis of a patient's clinical profile.

\section{Acknowledgements}

The authors thank Susanne Brown and Laura Grande for their assistance with data collection. We are also very grateful to the patients and staff of the Brockton/West Roxbury VAMC SCI Service. This work was supported by a grant from the Claude D Pepper Geriatric Research and
Training Center from the NIA-AG08812-05, and in part by NIH/NIA grants AG00599 and AG04390, and a grant from the Education and Training Foundation of the Paralyzed Veterans Association. Dr Gurwitz is the recipient of Clinical Investigator Award K08 AG00510 from the National Institute on Aging, National Institutes of Health, Bethesda, Maryland, USA.

\section{References}

1 Pedersen E. Regulation of bladder and colon-rectum in patients with spinal lesions. J Auton Nerv Sys 1983; 7: 329-338.

2 Menardo G et al. Large-bowel transit in paraplegic patients. Dis Colon Rectum 1987; 30: $924-928$.

3 Nino-Murcia M, Stone JM, Chang PJ, Perkash I. Colonic transit in spinal cord-injured patients. Invest Radiol 1990; 25: 109-112.

4 Cosman BC, Stone JM, Perkash I. Gastrointestinal complications of chronic spinal cord injury. J Amer Paraplegia Soc 1991; 14: $175-181$.

5 Stone JM, Nino-Murcia M, Wolfe VA, Perkash I. Chronic gastrointestinal problems in spinal cord injury patients: a prospective analysis. Am J Gastroenterol 1990; 85(9): $1114-1119$.

6 Longo WE, Ballantyne GH, Modlin IM. Colorectal disease in spinal cord patients. Dis Col and Rectum 1990; 33: 131-134.

7 Gore RM, Mintzer RA, Calendoff L. Gastrointestinal complications of spinal cord injury. Spine 1980; 6: $538-544$.

8 Glick ME, Haldeman S, Meshkinpour H. The neurovisceral and electrodiagnostic evaluation of patients with thoracic spinal cord injury. Paraplegia 1986; 24: 129-137.

9 Glick ME et al. Colonic dysfunction in patients with throacic spinal cord injury. Gastroenterology 1984; 86: 287-294.

10 Devroede G et al. Traumatic constipation. Gastroenterol 1979; 77: $1258-1267$.

11 Saltzstein RJ, Romano J. The efficacy of colostomy as a bowel management alternative in selected spinal cord injury patients. $J$ Am Paraplegia Soc 1990; 13: 9-13.

12 Stone JM Wolfe VA, Nino-Murcia M, Perkash I. Colostomy as treatment for complications of spinal cord injury. Arch Phys Med Rehabil 1990; 71: 514-518.

13 Teasell R, Allatt D. Managing the growing number of spinal cord-injured elderly. Geriatrics 1991; 46: 78 - 89 .

14 Nelson A et al. Descriptive study of bowel care practices and equipment in spinal cord injury. SCI Nursing 1993; 10: 65-67.

15 Hanson R, Franklin M. Sexual loss relation to other functional losses for spinal cord injured males. Arch Phys Med Rehabil 1976; 57: $291-293$.

16 Dunn KL, Galka ML. A comparison of the effectiveness of Therevac SB and Bisacodyl suppositories in SCI patient's bowel programs. Rehab Nurs 1994; 19: $334-338$.

17 Binard JE. Care and treatment of spinal cord injury patients. $J$ Am Paraplegia Soc 1992; 4: 235 - 249.

18 Fenton-Lee D, Yeo BW, Jones RF, Engel S. Colonic volvulus in the spinal cord injured patient. Paraplegia 1993; 31: $393-397$.

19 Banwell JG, Creasey GH, Aggarwal AM, Mortimer JT. Management of the neurogenic bowel in patients with spinal cord injury. Urol Clin North Am 1993; 20: 517-526.

20 Aisen ML et al. Clinical and Pharmacokinetic aspects of high dose oral baclofen therapy. J Am Paraplegia Soc 1992; 15: 211 216.

21 Levinson W, Ward G, Valleroy M. Care of the spinal-cordinjured patients after the acute period. J Gen Int Med 1989; 4: $336-348$.

22 Beuret-Blanquart $\mathrm{F}$ et al. Colonic transit time and anorectal manometric anomalies in 19 patients with complete transection of the spinal cord. J Auton Nerv Sys 1990; 30: 199-208.

23 Meshkinpour HN, Nowroozi F, Glick ME. Colonic compliance in patients with spinal cord injury. Arch Phys Med Rehabil 1983; 64: $111-112$.

24 Taylor TKF, Coolican MJR. Injuries of the conus medullaris. Paraplegia 1988; 26: $393-400$. 
25 Nino-Murcia M, Friedland GW. Functional abnormalities of the gastrointestinal tract in patients with spinal cord injuries: evaluation with imaging procedures. Am J Radiology 1992; 158: $279-281$.

26 Doraisamy P. Bowel management in patients with spinal cord lesions. Singapore Med J 1984; 25: 70 - 72 .

27 Longo WE, Ballantyne $\mathrm{CH}$, Modlin IM. The colon, anorectum, and spinal cord patient; functional alterations of the devervated hindgut. Dis Colon Rectum 1989; 32: 261-267.

28 Emerick CA. Nursing management of the neurogenic bowel ARN J 1979; 4: 16-18

29 Feldman M, Schiller LR. Disorders of gastrointestinal motility associated with diabetes mellitus. Ann Intern Med 1983; 98: $378-$ 384.

30 Maxton DG, Whorwell PJ. Functional bowel symptoms in diabetes - the role of autonomic neuropathy. Postgrad Med J 1991; 67: $991-993$.

31 Frankel HL et al. The value of postural reduction in the initial management of closed injuries of the spine with paraplegia and tetraplegia. Paraplegia 1969; 7: 179-192.

32 Harari D et al. Constipation: Assessment and management in an institutionalised population. J Am Geriatr Soc 1994; 42: 1-6.

33 Harari D et al. Correlates of regular laxative use in frail elderly persons. Am J Med 1995; 99(4): 513-518.

34 Whitehead WE et al. Constipation in the elderly living at home: Definition, prevalence and relationship to lifestyle and health status. J Am Geriatr Soc 1989; 37: 423-429.

35 Traube M, McCallum RW and members of American College of Gastroenterology's Committee on FDA Related Matters. Calcium-channel blockers and the gastrointestinal tract. $\mathrm{Am} \mathrm{J}$ Gastroenterol 1984; 79(11): $892-896$.

36 Brock C et al. Adverse effects of iron supplementation: A comparative trial of a wax-matrix iron preparation and conventional ferrous sulfate tablets. Clin Ther 1985; 7: 568 - 573

37 Monane M, Avorn J, Beers MH, Everitt DE. Anticholinergic drug use and bowel function in nursing home patients. Arch Intern Med 1993; 153: 633-638.

38 Warnes H, Lehmann HE, Ban TA. Adynamic ileus during psychoactive medication. Canad Med Ass J 1967; 96: 1112 - 1113 .

39 Kreek M-J, Schaeffer RA, Hahn EF, Fishman J. Naloxone, a specific opioid antagonist, reverses chronic idiopathic constipation. Lancet 1983; (Feb) 5: $261-262$.

40 Edwards IR, Coulter DM, Macintosh D: Intestinal effects of captopril. Br Med J 1992; 304: 359-360.

41 Hollingworth J, Alexander-Williams J. Non-steroidal antiinflammatory drugs and stercoral perforation of the colon. Ann $R$ Coll Surg Eng 1991; 73: 337 - 340 .

42 Bracken B et al. Incidence of acute traumatized hospitalized spinal cord injury in the United States, 1970-1977. Am J Epidemiol 1981; 113: 615-622.

43 Varma JS et al. Differential effects of sacral anterior root stimulation on anal sphincter and colorectal motility in spinally injured man. Br J Surg 1986; 73: $478-482$.
44 Waldron DJ et al. Multiple sclerosis: assessment of colonic and anorectal function in the presence of faecal incontinence. Int $J$ Colorect Dis 1993; 8: 220 - 224.

45 Tudor L. Bladder and bowel retraining. Am J Nurs 1970; 70: $2391-2393$

46 Colachis SC. Autonomic hyperreflexia with spinal cord injury. $J$ Am Paraplegia Soc 1992; 15: 171-186.

47 Aaronson MJ, Freed MM, Burakoff R. Colonic myoelectric activity in persons with spinal cord injury. Dig Dis Sci 1985; 30: $295-300$

48 Pietrusko RG. Use and abuse of laxatives. Am J Hosp Pharm 1977; 34: 291 - 300

49 Castle SC, Cantrell M, Israel DS, Samuelson MJ. Constipation prevention: empiric use of stool softeners questioned. Geriatrics 1991; 46: $84-86$

50 Harari D, Gurwitz JH, Minaker KL. Constipation in the elderly. J Am Geriatr Soc 1993; 41(10): $1130-1140$.

51 Hamilton JW, Wagner J, Burdick BB, Bass P. Clinical evaluation of methylcellulose as a bulk laxative. Dig Dis Sci 1988; 33(8): $993-998$

52 Mamtani R, Cimino JA, Kugel R, Cooperman JM. A calcium salt of an insoluble synthetic bulking laxative in elderly bedridden nursing home residents. J Am Coll Nutr 1989; 8: $554-556$

53 Lederle FA et al. Cost-effective treatment of constipation in the elderly: A randomized double-blind comparison of sorbitol and lactulose. Am J Med 1990; 89: $597-601$.

54 Puxty JA, Fox RA. Golytely: a new approach to faecel impaction in old age. Age Ageing 1986; 15(3): $182-184$

55 Rouse M, Mahapatra M, Atkinson SN, Prescott P. An open randomised parallel group study of lactulose versus ispaghula in the treatment of chronic constipation in adults. Br J Clin Pharm 1991; 45: $28-30$.

56 King JC, Currie DM, Wright E. Bowel training in spina bifida: importance of education, patient compliance, age and anal reflexes. Arch Phys Med Rehabil 1994; 75: 243-247.

57 Stiens SA. Reduction in bowel program duration with polyethylene glycol based Bisacodyl suppositories. Arch Phys Med Rehabil 1995; 76: 674-677.

58 Liptak GS, Revell GM. Management of bowel dysfunction in children with spinal cord disease or injury by means of the enema continence catheter. J Pediatr 1992; 120: 190 - 194.

59 Penrod LE, Hegde SK, Ditunno JF. Age effect on prognosis for functional recovery in acute, traumatic central cord syndrome. Arch Phys Med Rehabil 1990; 71: 963 -968.

60 Holdstock DJ, Misiewicz JJ, Smith T, Rowlands EN. Propulsion (mass movements) in the human colon and its relationship to meals and somatic activity. Gut 1970; 11: $91-99$.

61 O'Keefe EA, Talley NJ, Tangalos EG, Zinsmeister AR. A bowel symptom questionnaire for the elderly. J Geront 1992; 47: M116-M121. 